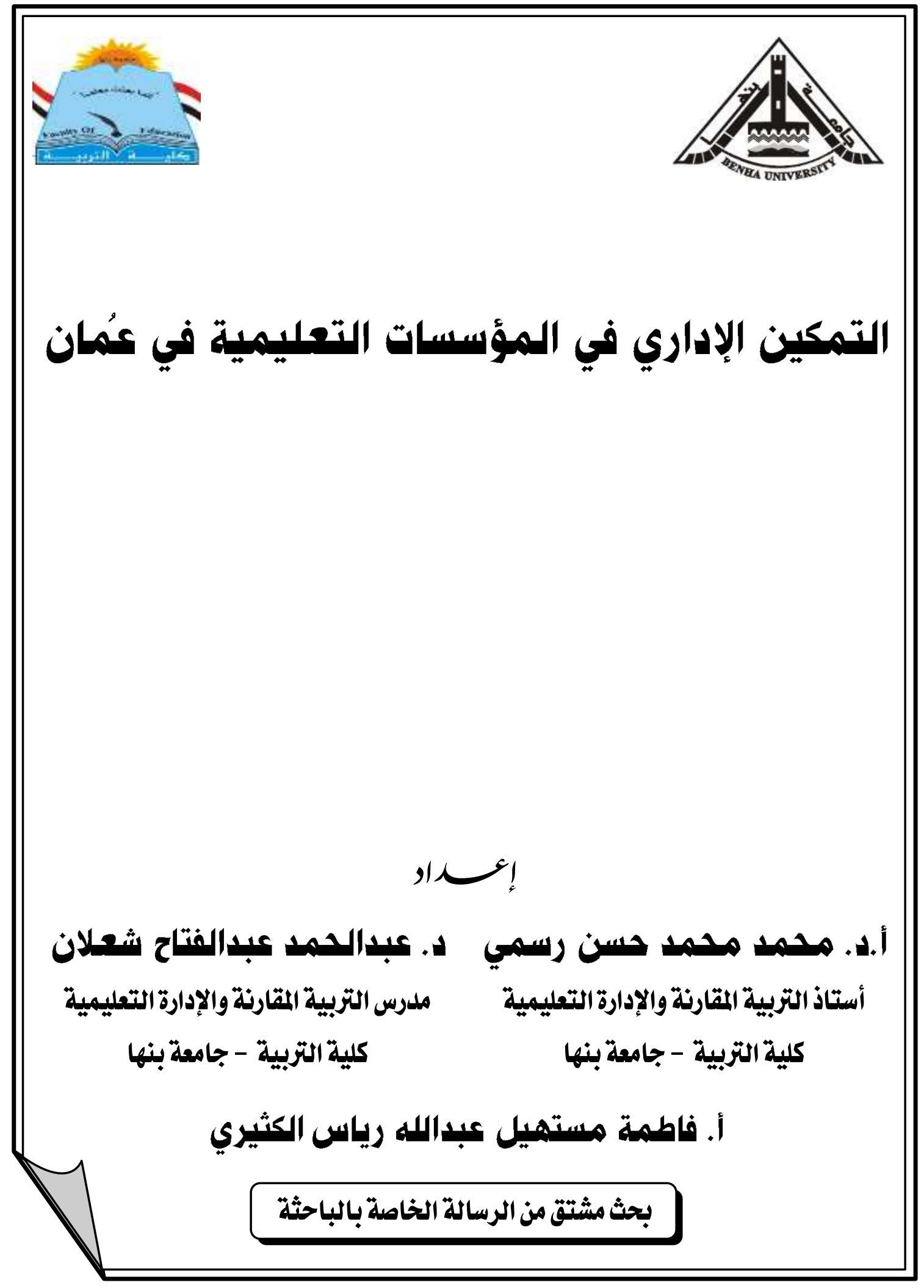




\section{التمكين الإداري في المؤسسات التعليمية في عُمان}<smiles>[AlH]C[AlH2]</smiles>

د. عبدالدمد عبدالفتاح شعلان

ملرس التربية المقارنةوالإدارة التعليمية

كلية التربية - جامعة بنها
أ.د. همهم هحمد هسن رسمي

استاذ التربية المقارنة والإدارة التعليمية

كلية التربية - جامعة بنها

أ أ. فاطمة مستهيل عبدالله رياس الكثيري

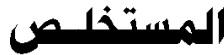

يهدف البحث إلى تحديد أبعاد التمكين الإداري في مدار التعليم الأساسي بسلطنة عمان، والكثف عن دور التمكين الإداري، والتعرف على واقع تمكين مدراء المدارس التعليم

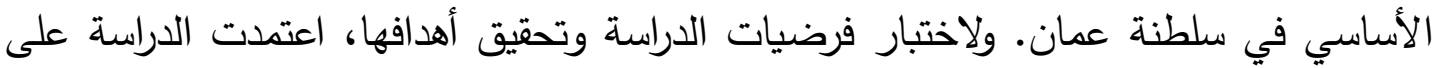

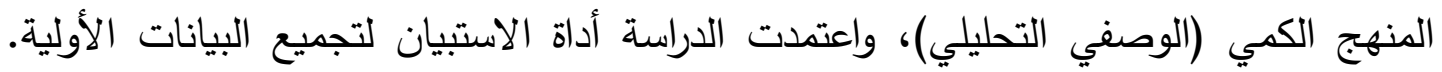

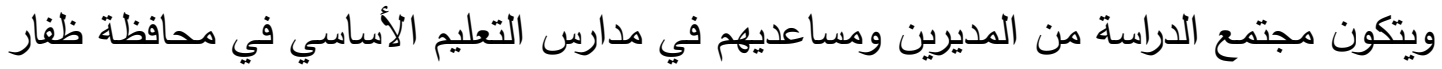

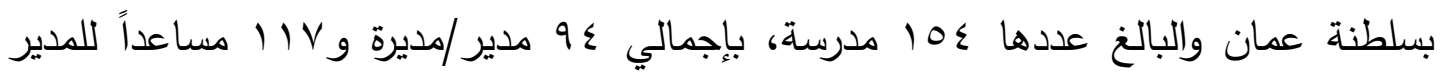

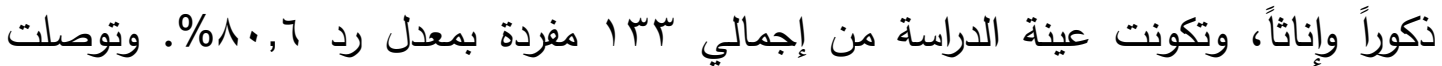

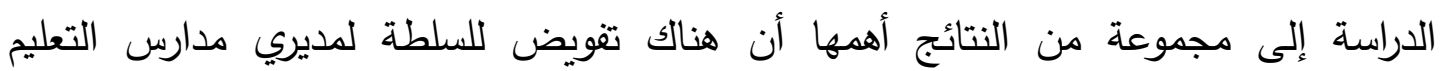
الأساسي ومساعديهم بمحافظة ظفار من جانب إدارة الدديرية العامة للتربية والتعليم بالدحافظة، وأوصت الدراسة بضرورة منح إدارات المدارس المزيد من الصلاحيات في حل المانس المشكلات المدرسية التي قد تواجههم بما يتناسب مع طبيعة المكان والزمان والأفراد. 


\section{Ahstract}

The research aimed to determine administrative empowerment dimensions in primary schools in Amman, discover the role of administrative empowerment, and identify the reality of empowering primary school managers in Amman. To test study hypotheses and achieve its objectives, the study used the quantitative (analytical descriptive) method and used the questionnaire to collect the primary data. The population of study consists of managers and their assistants of 154 primary schools in Zafr Governorate in Amman (94 male/female managers and 117 male/female assistants). The sample of study consists of 133 individuals with a response rate of $80.6 \%$. The study found a number of results and the most important of which is that there is a delegation of power to primary school managers and their assistants in Zafr Governorate by the general administration of education in the governorate. The study recommended that it is important to grant school managers more powers in solving school problems, which might face them in a way that is consistent with the nature of place, time, and individuals. 


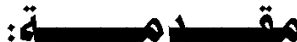

تعد عملية تطوير التعليم في ظل الثورة المعرفية والتكنولوجية التي تثهدها المجتمعات الحديثة من أهم المراحل التعليمية، حيث تتبلور في الأعمال الإدارية وفي التتوع الوظيفي، وذلك لإعداد الكوادر العلمية المؤهلة والمدربة والقادرة على مواجهة التغيرات المتسارعة في كافة النواحي الحياتية وقيادة المؤسسات وتوجيهها بالثكل العلمي القادر على إحداث التتمية الثاملة والسليمة،

وبالتالي تحقيق الأهداف والغايات التي تسعى المؤسسات العلمية والتربوية إلى تحقيقها (1). والإدارة ليست نتاجاً للتنمية الاجتماعية والاقتصادية فقط، ولكنها تعد سر نجاح التنمية وتميزها، ويكمن ذلك في كيفية توظيف واستغلال الثروات واستخدام القوى البشرية وحملها على

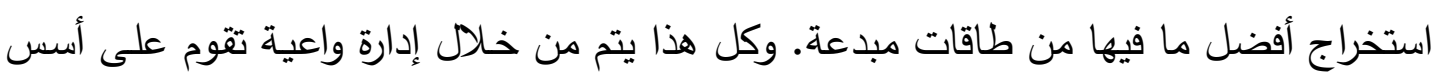
عملية سليمة وصحيحة(؟). كما أن الإدارة التعليمية تعد من أهم الإدارات الحديثة، فهي عبارة عن مجموعة من

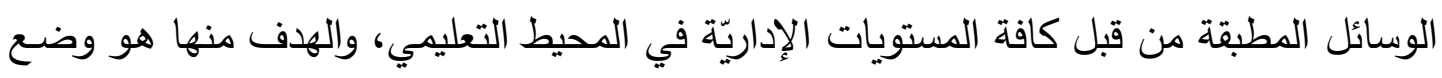

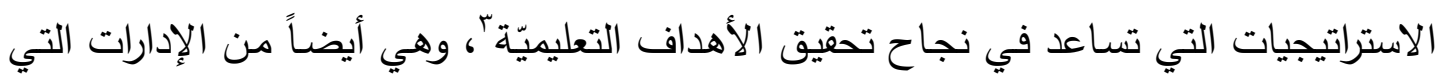

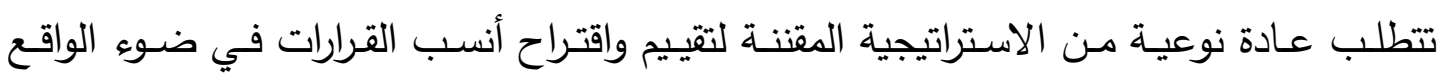
التعليمي بثكل خاص والواقع البشري بشكل عام. وبالإضافة إلى ذلك، لا يمكن تجاهل أهمية عملية التمكين الإداري، ومدى تأثيرها في لئنسي تجويد العمل والعملية التعليمية ككل، وذلك من خـلال تفويض المدراء والسماح لهم باتخاذ القرارات ضمن الصلاحيات المسموح بها، وتوفير كافة الإمكانات والاحتياجات الضرورية التي تدعم التمكين الإداري وتعزز من قيمة الكادر الإداري مثل المكافآت المعنوية والمادية.

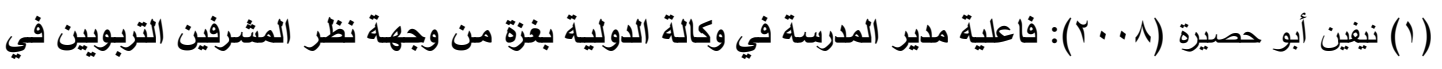

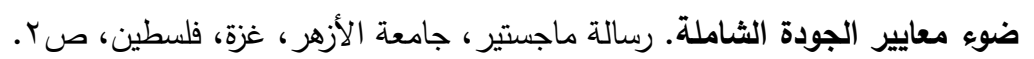

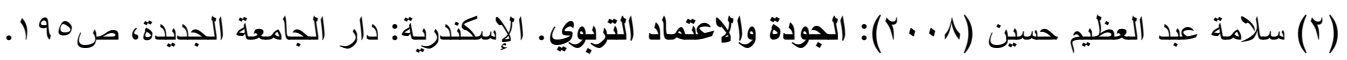

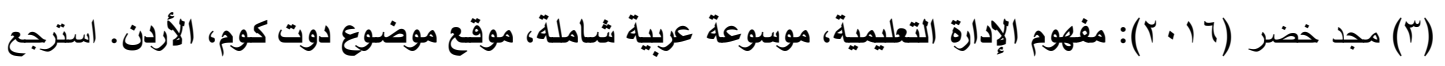

\section{rrq}

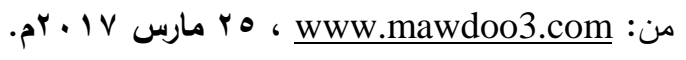


وقد فرضت التحولات التعليميـة المعاصـرة ضـغوطاً متزايدة على التعليم، لذا أصبح

البحث عن صيخ فاعلية التعليم ضـرورة اجتماعية، فقد سعت كثير من الدول إلى مراجعـة أنظتها التربويـة التعليمية مراجعة شاملة وجذريـة بهدف تفعيل المدرسـة، وتمكين المتعلم من فن فئن

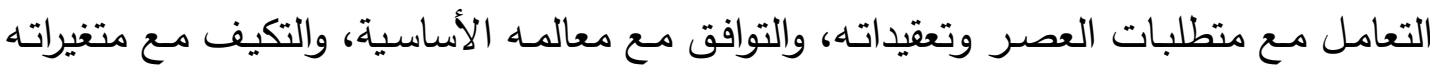
المختلفة والسريعة (1).

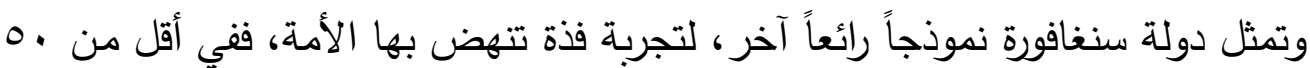

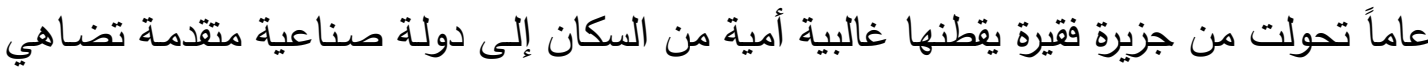

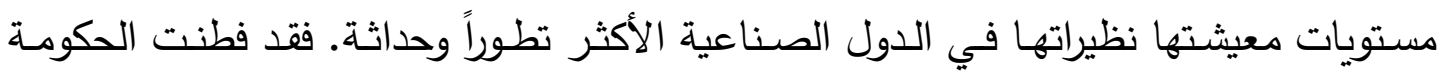

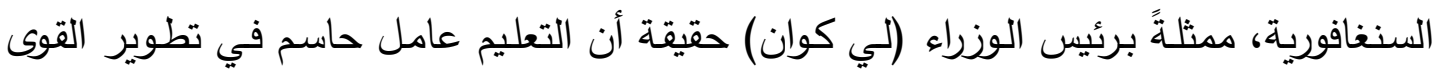

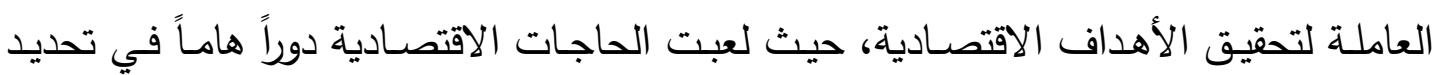

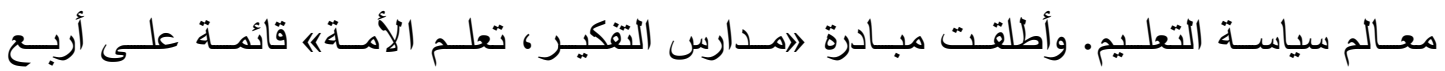

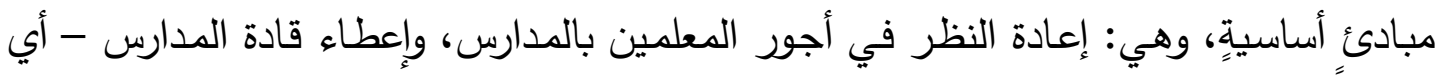

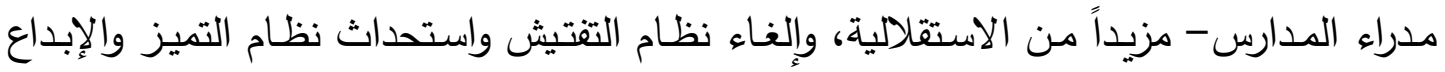
المدرسي, وتقسيم المـارس لمجموعـات يشـرف عليها لجـان متخصصـة نعمل على تطوير

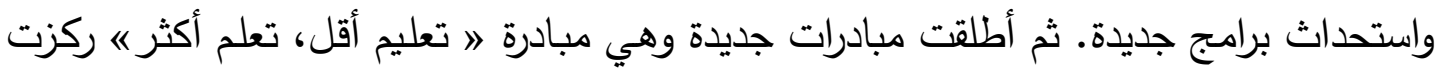
على طرق التدريس وتقليل حجم الدحتوى لفتح باب وجال للتفكير (؟).

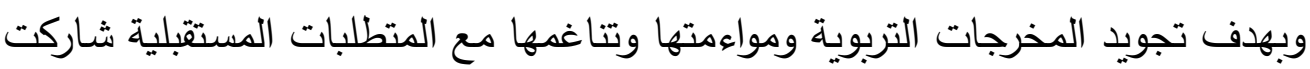

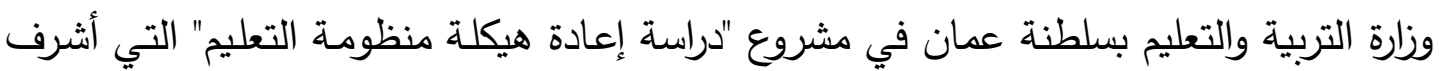

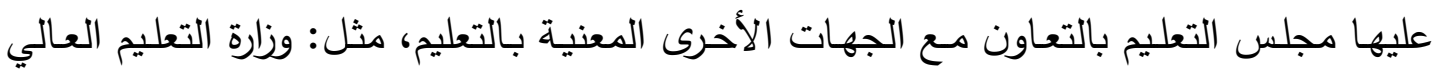

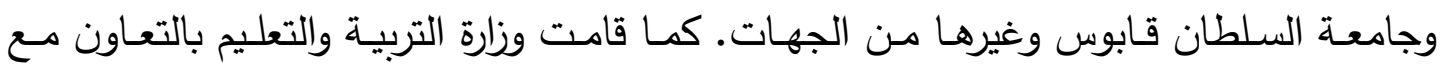

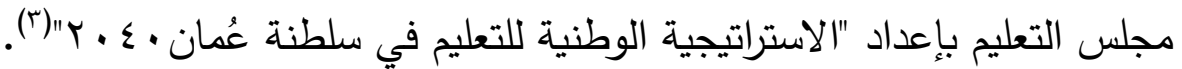

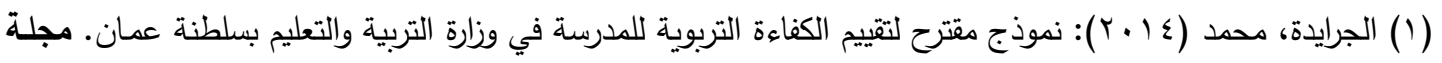

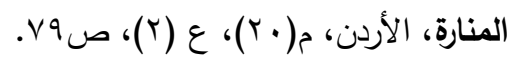

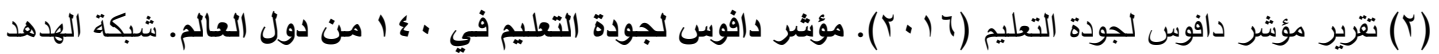

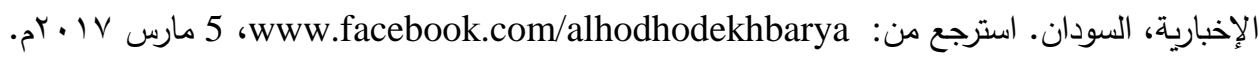

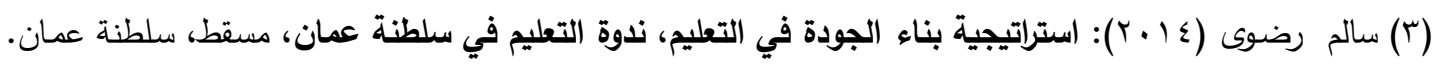

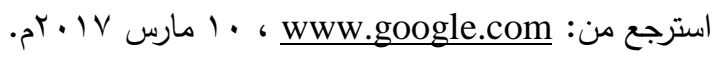




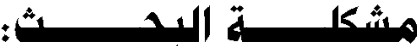

بالرغم من الجهود المبذولة من قبل وزارة التربية والتعليم بسلطنة عمان لتطوير جودة

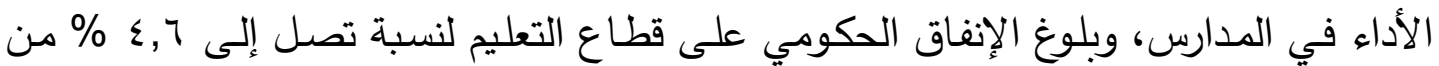

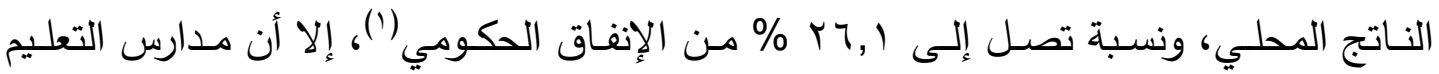

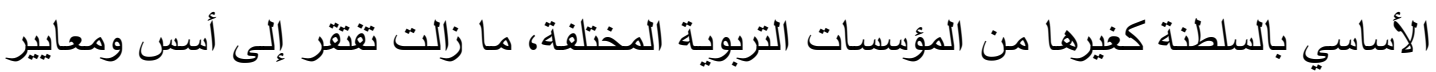

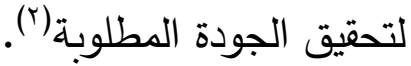

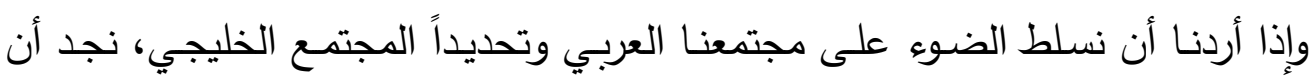

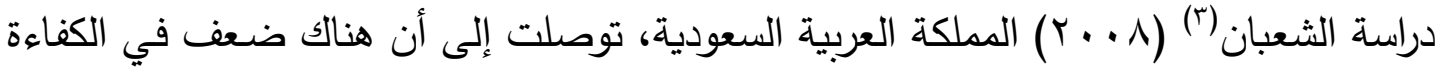

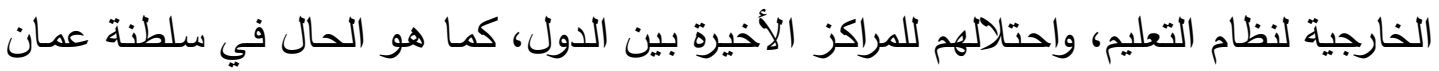

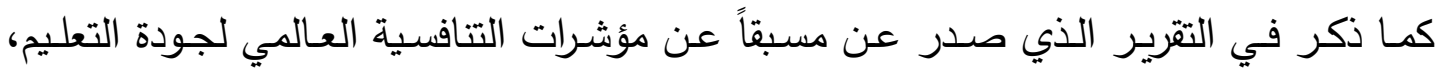

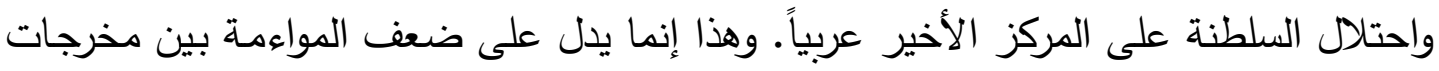

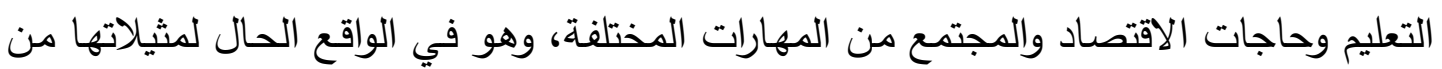
دول الخليج في مستوى تحقيق الجودة في التعليم. ومن هنا يمكن صياغة مثكلة البحث في السؤال الرئيسي التالي: كيف يمكن تمكين مدراء مدارس التعليم الأساسي بسلطنة عمان؟

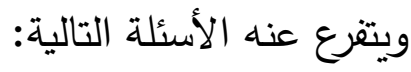

1- ما هي أبعاد التمكين الإداري على مدارس التعليم الأساسي بسلطنة عمان؟

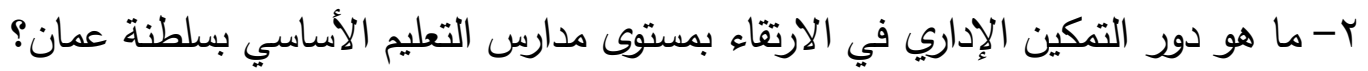

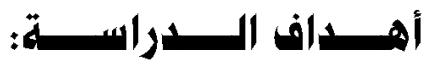

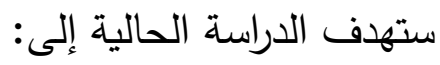
1- تحديد أبعاد التمكين الإداري على مدارس التعليم الأساسي بسلطنة عمان.

(1) منظمة الاقتصاد والتعاون الدولية (10 ب): أفضل تسع دول عربية في مستوى التحصيل الدراسي. موقع Tops Arabia

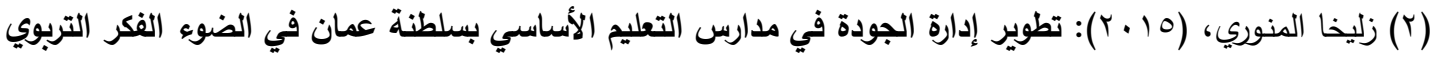

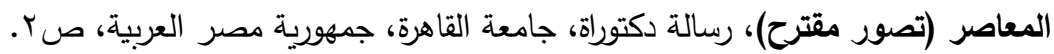

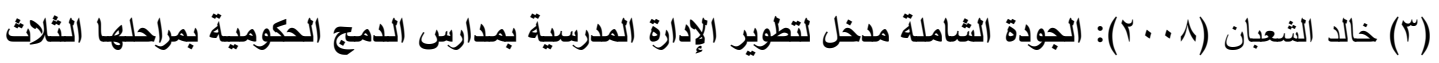

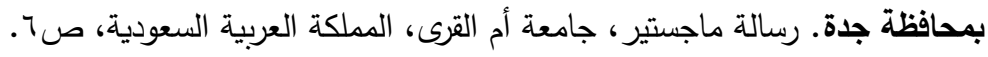


r- الكثف عن دور التمكين الإداري في مدارس التعليم الأساسي بسلطنة عمان.

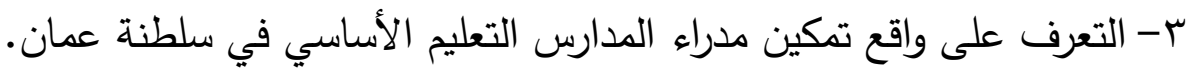

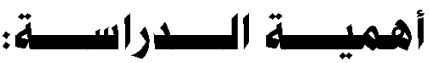

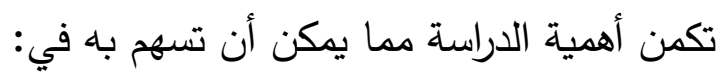

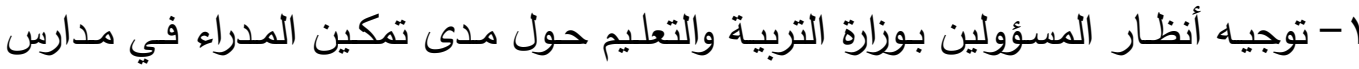

$$
\text { التعليم الأساسي. }
$$

r- تسليط الضوء على تمكين مدراء المدارس في مدارس التعليم الأساسي بسلطنة عمان

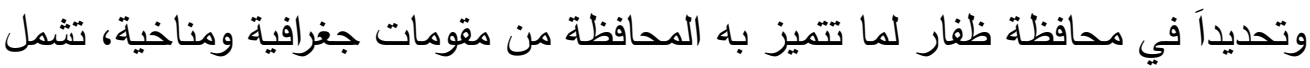
البيئة الساحلية، الجبلية، الصحراوية، السهلية؛ وذلك يمكن من تطبيق الدراسة في بيئات متتوعة ومختلفة. r- تثجيع الباحثين لإجراء المزيد من الدراسات والبحوث حول موضوع الدراسة.

\section{حسدود البـدراسبة}

ستلتزم الدراسة بالحدود التالية: الية العدود العلمية: التمكين الإداري وأبعاده.

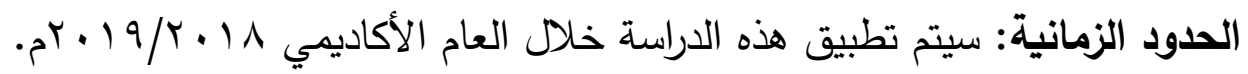
الحدود المكانية: ستقتصر هذه الدراسة على مدارس التعليم الأساسي بمحافظة ظفار بسلطنة عمان.

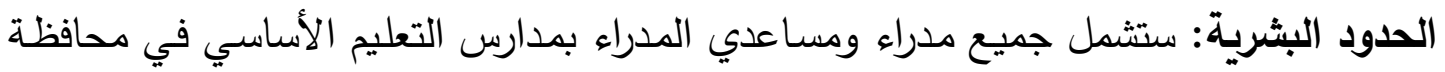
ظفار بسلطنة عمان.

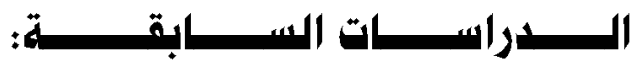

سيتم استعراض مجموعة من الدراسات والبحوث السابقة التي تتاولت مدى تمكين مدراء

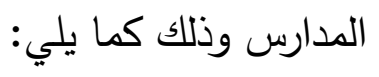

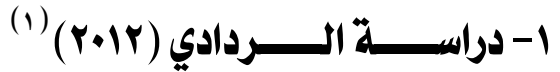

هدفت الدراسة إلى التعرف على مستوى التمكين الإداري ومستوى القدرة على اتخاذ

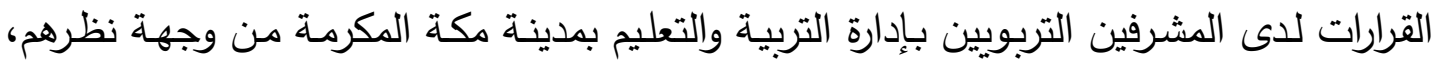

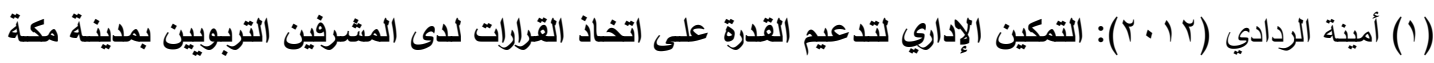

$$
\text { المكرمة، جامعة أم القرى ، المملكة العربية السعودية. }
$$


واستخدم الباحث المنهج الوصفي في دراسته، كما توصلت الدراسة إلى نتائج، نذكر أهمها، أن مستوى ممارسـة محاور عملية التمكين الإداري لدى المشرفين التربويين بإدارة التربية والتعليم بمدينة مكة المكرمة كانت بدرجة غالباً باستثناء البعد الثالث وهو التحفيز الذاتي وجاء بدرجة

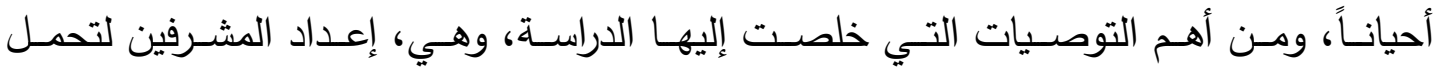
المسؤوليات الجديدة وتمكينهم مـن خـلال دورات تدربيـة تعينهم على ذلك، ومـنح المشـفين التربوينين مزيداً من الصـلاحيات وخاصـة في اتخاذ القرارات في النواحي التعليمية، وتشخيص الأسباب التي قد تحد من نشر التمكين الإداري لدى المشرفين التربوين.

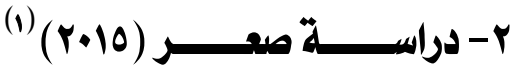

هدفت الدراسة إلى تحديد درجة التمكين الإداري وعلاقته بالأداء الوظيفي لدى المشرفين

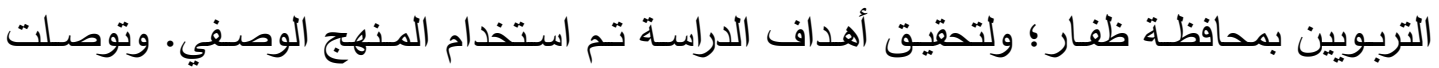
الدراسـة إلى نتائج، نـذكر أهمها، أن مستويات التمكين بأبعـاده الثلاثة (التفويض، الدافعيـة، التدريب والتأهيل) جاء بدرجة متوسطة من وجهة نظر المشرفيين التربويين. كما أوصت الدراسة بعدد من التوصـيات، أهمها، السـي إلى تفويض المزيـــ مـن الصـلاحيات والسلطة للمشرفين التربوين حتى يتمكنوا من أداء عملهم بطريقة تحفظ لهم حقهم بالمشاركة في الإدارة من خلال القوانين والأنظمـة التي تسكل عملية تفويض السلطة وبيان حدودها ومجالاتها وصـلاحياتها، بالإضـافة إلى ضــرورة وضـع خطط واضـحة وهادفة للتدريب والتأهيـل مـن خـلال عقد دورات تدربيية متخصصة تؤهل الكادر الإشرافي للعمل.

\section{r) ب- دراسـ}

هدفت الدراسـة إلى التعرف على واقـع التمكين الإداري لدى مديري مدارس التعليم مـا بعد الأساسي في محافظة الباطنة شمال في سلطنة عمان، كذلك هدفت إلى معرفة أثر متغيرات الدراسة: النوع الاجتمـاعي، وسنوات الخبرة، والمؤهل العلمي في تقديرات أفراد الدراسـة لواقع التمكين الإداري. وقد توصلت الدراسة إلى نتائج، نذكر أهمها، أن تقديرات مديري مدارس التعليم ما بعد الأساسي في

(1) سامية صعر (10 + (1): التمكين الإداري وعلاقته بالرضا الوظيفي للى المشرفين التربويين بمحافظة ظفار، رسالة

ماجستير ، جامعة ظفار ، سلطنة عمان.

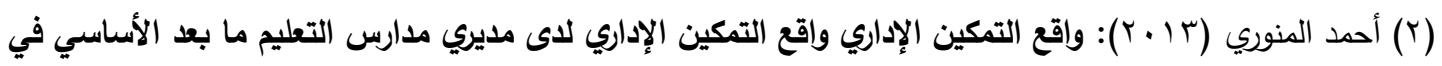




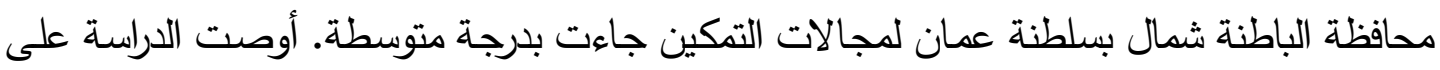

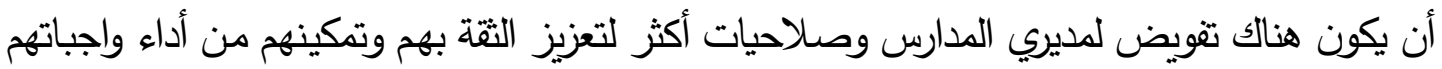
بفاعلية، وتوفير وزارة التربية والتعليم مناخا تتظيميا صحيا يسمح بممارسة مجالات التمكين الإداري لمديري المدارس بإعادة النظر في نظام الحوافز ، والمكافآت، وصنع الاستراتيجيات لتمكين مديري المدارس وتدريبه على الأساليب الحديثة في مجال صنع القرار واتخاذه وآليات تتفيذه.

\section{الأسس النظرية لعملية التمكين الإداري في المؤسسات التعليمية}

مفهوه التمكين الإداري في المؤسسات التعليمية ؛

ظهر مفهوم التمكين في القرن العشرين وتحديداً في نهاية الثمانينات، ولاقى رواجاً بصورة

أكبر في مطلع التسعينات، نتج عنه التركيز على العنصر البشري داخل المنظمات التربوية.

ولا شك أن الاهتمام بمفهوم تمكين العاملين بشكل عام والمدراء بصورة خاصسة يشكل

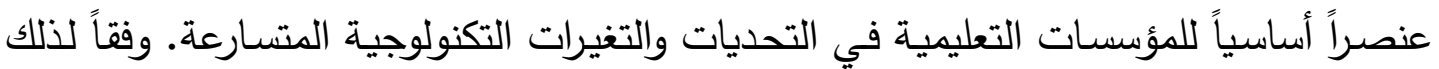

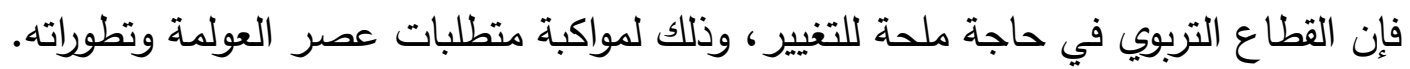

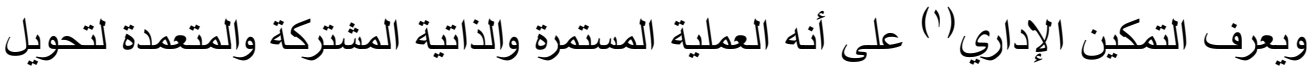
العاملين إلى الأفراد الواعين بأنفسهم وبظروفهم الاجتماعية وذلك من خـلال السلوك الثـامل والانتقادي والتحويلي المرتكز على تفاعلاتهم الاجتماعية الخاصة.

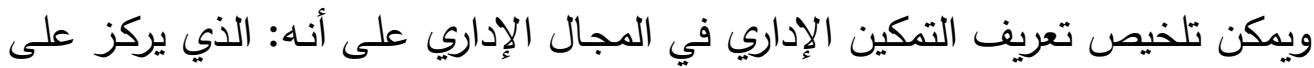

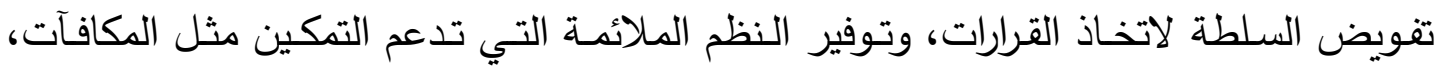
والتحسين المستمر، وبناء فريق عمل قادر على جعل هذا المجال ذو سلطة إدارية ناجحة. وبهذا تقوم فكرة التمكين الاداري على قيام الادارة العليا بمنح السلطة والمسؤولية والثقـة التامة للعاملين لأداء مهامهم بكل أريحية وخلق شعور ايجابي لدى العاملين يمثل دافعاً مهما للعمل.

\section{أهمية التمكين الإداري في المؤسسات التعليمية:}

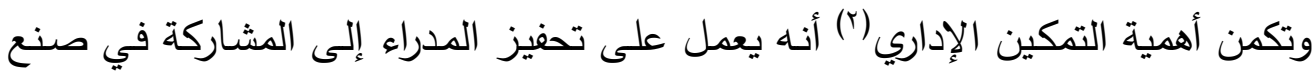

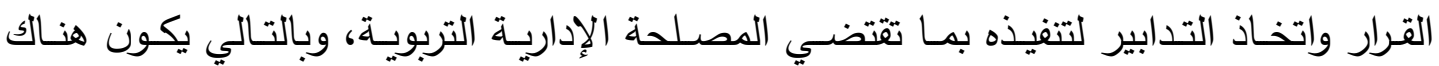

(1) Fandiño, Yamith J. "Research as a means of empowering teachers in the 21st century." Educación y educadores 13.1 (2010). P112.

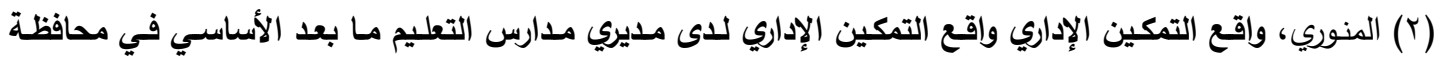
الباطنة شمال بسلطنة عمان، مرجع سبق ذكره، ص بr. 
سياسات جيدة في الأداء الإداري المدرسي، الذي بإمكانه أن يسهم في تأكيد مشاركة المدراء في

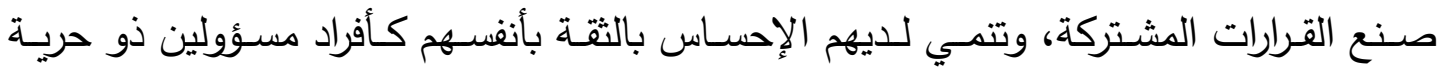
واستقلالية في صنع القرارات التربوية عامة والمدرسية بشكل خاص.

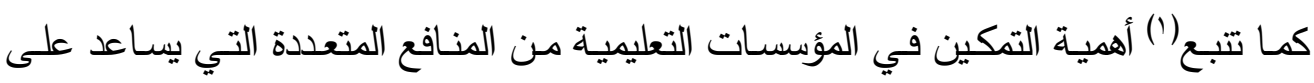
تحقيقها. حيث يؤدي التمكين إلى رفع مستوى طلب الأفراد على التدريب والتأهيل وتطوير الفعالية من خلا التدريب الثامل وتبادل المعرفة. وعلاوة على نلك، يعمل التمكين على رفع مساهمات وأفكار العاملين بالطريقة التي تؤدي إلى زيادة القرات الابتكارية وتعزيز مشاعر العاملين الإيجابية.

\section{أهداف التمكيز الإداري في المؤسسات التعليمية :}

ولكي تحقق (r) المؤسسة التعليمية أهدافها، فعلى الرؤساء إشراك المدراء في عملية اتخاذ القرارات، لأن المؤسسـة التعليمية بحاجة إلى خبراتهم ومهاراتهم ومعلوماتهم، لتحقيق الأهداف التي تنشـها المؤسسـة التعليميـة وتطوق إلى تحقيقها، وذلك باستخدام نظم وسياسـات إداريـة حديثة لتتناسب مـع التحديات العالمية المعاصرة، حيث أن التمكين الإداري يعتبر أداة أساسية لجعل المؤسسة التعليمية قادرة على مواجهة التحديات المستقبلية. ولقد حددت(r) بعض الدراسات أهداف التمكين، كالتالي: خلق الولاء للمنظمة التعليمية. توظيف أقصى طاقات العاملين من أجل المدرسة. تبني العاملين والتزامهم بأهدافهم. هالانخراط في التحسين المستمر لتلبية رغبات وتوقعات العملاء أو ما يفوقها. توفير الظروف التي تجعل الفرد قادراً على تحقيق رضا المستفيدين الطلاب.

(1) Alshbiel, Seif Obeid. "The Impact of the Managerial Empowerment in the performance of Investment Funds in the Jordanian PublicUniversities." Global Journal of Management And Business Research, Volume 14 Issue 5 Version 1.0 Year 2014, (2015). P4.

(Y) عبدالعالي دبلة، وفاء العمري، آلية التمكين الإداري في الفكر التظيمي الحديث، مرجع سابق، صلهـ.

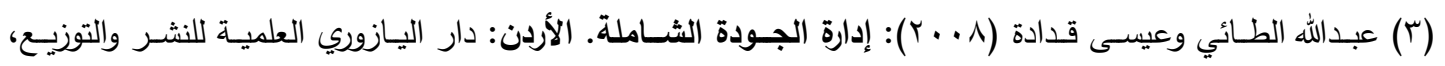




$$
\text { تتحصر مبادئ(1) التككين الإداري بمكونات مفهومها في الآتي: }
$$

وضوح الأهداف: يقوم هذا المبدأ على ضمان الفهم والوعي لكامل لاى العاملين، كما يرسم التصورات التامة لفلسفة الإدارة العليا وتوجيهها للأفراد العاملين. الدافعية: ينحصر هذا المبدأ في تثجيع العاملين لتقبل مفهوم التمكين الإداري وبيان مساهنهم في تحقيق الأدوار التنظيمية، والتثجيع المستمر نحو بناء فرق العمل ونشر ثقافة الأبواب المفتوحة من قبل الإدارة العليا في ملاحظاتهم وتعليقات العاملين. تعليم العاملين: يتجسد في هذا المبدأ نشر ثقافة التعليم والتعلم بين لعاملين في الددارس ومؤسسات التعليم، حيث يساهم نشر مثل هذه الثقافة زيادة فاعلية العاملين وتثجيعهم نحو انجاز مهامهم وتحقيق النجاح. الإنجاز : ينحصر هذا المبدأ في قبول العاملين لتلك الصـاحيات والمسؤوليات وضمان المسؤولية لها لتتوازى مع الإنجاز . • الرغبة في التغيير: يقود التمكين الإداري من خلال هذا المبدأ إلى البحث عن الأساليب الحديثة لمواكبة التطورات العصرية في المدارس والمؤسسات التعليمية، كما يدعو هذا المبدأ الإدارة العليا في المدارس والمؤسسات التعليمية إلى تثجيع العاملين نحو التغيير وحب التطوير.

نكران الذات: مبدأ يحارب اتباع أنماط الإدارة القديمة وينبذ السيطرة والتسلط. • الاحترام: يقوم هذا المبدأ على إبراز أهمية العاملين في الددارس والمؤسسات التعليمية التي يعملون بها، مـن خـلال دعم تطوير أعمالهم وضـمان الإبداع فيه. كما يشكل الاحترام بين العاملين أنفسهم والإدارة العليا جوهراً لخطوط الاتصال والتواصل.

(1) Weaam Khalayleh, Raed Masadeh, Musa Al lozi The Role of Administrative Empowerment on the Work teams Performance: A Literature Review. Centre of Excellence for Scientific \& Research Journalism, (2018). Vol(4), No(3). 


\section{أساليب التمكين الإداري في المؤسسات التعليمية :}

يرى البعض(') أنه من الممكن تحقيق التمكين من خلال الأساليب التالية: "الأسـاليب الهيكلية (التمكين الهيكلي): يتمثل في أقل عدد من المستويات الإداريـة، والتي تيسر تدفق المعلومات في اتجاهين، وذلك بإتباع المبادئ التالية في تطبيقه: بناء الوحدات التظيمية استتادًا إلى مجموعة العمل الأولية التي سيكون لها قائدها المميز • يخطط وينظم ويقدم ويقيم رئيس وأعضاء كل وحدة عملهم ضمن إطار معين. يتم تكوين الوحدة بطريقة تمكنها من حل المشاكل التي تواجه تحقيق الأهداف. • تمكين الوضـع الإداري للمديرين: يتميز بقدرته على تفويض بعض سلطاته لمرؤوسيه في مجال التخطيط والتنفيذ وتقييم الأداء، وقدرته على تغيير نمط المراقبة البيروقراطية إلى نمط آخر استنادًا إلى الثقة والاحترام المتبادل. المشـاركة في حل المشـاكل- تشـص كل وحدة (فريـق عمـل) المشـاكل وتحدد الحلـول

المناسبة لهم ضمن الإمكانيات المتاحة، وفي حدود القيود والعوائق المفروضة عليها.

\section{أبعاد التمكين الإداري في المؤسسات التعليمية:}

يمكن بلورة أبعاد التمكين الإداري، وحصرها في خمسة أبعاد محددة وواضحة، وهي

كالتالي: (تفويض السلطة، فرق العمل، التدريب والتعليم، الاتصال الفعال، تحفيز العاملين).

\section{:Delegation of Authority ${ }^{\left({ }^{(}\right)}$}

يمكن القول أن هذا البعد يمثل العنصـر والمحرك الأساسـي للتمكين الإداري، الذي

تتوقف عليه صـاحية المدراء في مزاولة أعمالهم بدون قيود وتحديد مسؤولياتهم بشكل مستقل. فـالتفويض يعني مـنح المـدراء الصـلاحية في المسـتوى الإداري، ولـه الحق في اتخـاذ القـرار وإصدار الأوامر في حدود الصدلاحيات المسموح له بها.

(1) Hamzeh Al haar. The Impact of Administrative Empowerment on the Organization Performance at Jordanian Industrial Companies. Canadian Social Science, (2016). Vol(12), No(1).

(Y) صفاء جواد (Y (Y. (Y): أثر التمكين الإداري على الرضـا الوظيفي لدى العاملين في هيئة التعليم التقني. مجلة كلية

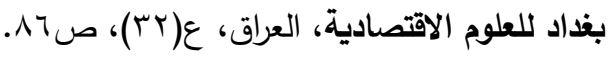




\section{التعليــمم والتـــدريــبـ ('Personal Development}

التدريب من العناصـر الأساسية في تطوير المدراء وصـقل مهاراتهم وتتمية قدراتهم،

وتساعدهم في القيام بأعمالهم بشكل أكثر فعالية، وتعزز من شخصياتهم بالتقنيات العالية التي يكتسبونها من الدورات والبرامج التدريبة التي توفرها لهم المديريـة التعليمية سنوياً وبشكل مستمر لمواكبة كافة التغيرات والتطورات الحديثة في مختلف المجالات التربوية الإدارية والمدرسية.

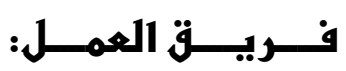

هو من الأسـاليب التي تعتمد عليها المنظمـات التربويـة الناجحة في تحقيق الأهداف المشتركة، بروح فريق واحد ذو تفكيرك مشترك، مبتعد تماماً عن الأنانية وجو المشاحنات التي لا تخلق إلا طاقات فاشلة منهكة. لذا مثل هذا البعد يدعو إلى العمل بنظام واحد يكفل تحقيق الهدف المشترك في إدارات المدارس بطاقة العمل الجماعي الإيجابي.

\section{:Developing Creative Behavior ${ }^{(")} \mathrm{J}$}

في ظل تسارع المتغيرات التكنولوجية والثورة المعلوماتية الهائلة في القرن الأخير ، بات الإبداع في التفكير وخلق طرائق ابتكار متنوعة من الأمور الضرورية، والتي لابد من استخدامها لحل المشكلات التي قد تواجه مدراء المدارس، مع توفير مناخ إداري بكافة الإمكانيات المادية والبشرية لتحقيق الأهداف ووسائل اتصال حديثة، تسهل عملية الاتصال الفعال.

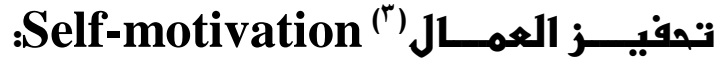

تكمـن في تعزيـز المـدراء على الكفـاءة الذاتيـة، وبالتـالي تحفزهم على تتفيذ المهام

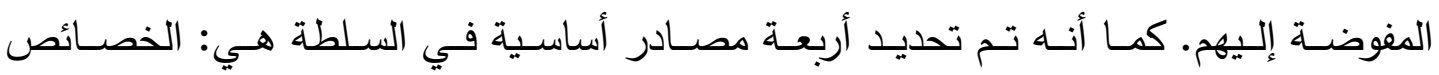
الشخصـية، والمنصسب، وفرصـة الوصـول إلى المعرفـة المتخصصـة، والخبرة، ويتوقع أن هذه المصادر تكفي لبناء الكفاءة الذاتية، والمقدرة على المشاركة في توفير المعلومات، والاستقلالية والحرية، والتغذية الراجعة مع الأفراد في المنظمة التربوية.

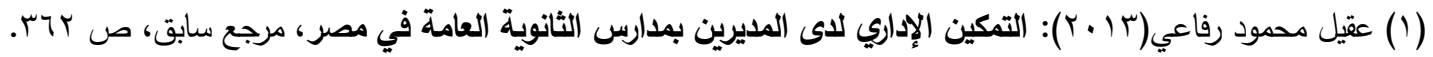

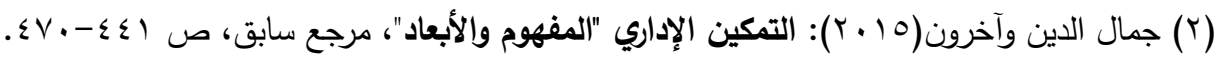

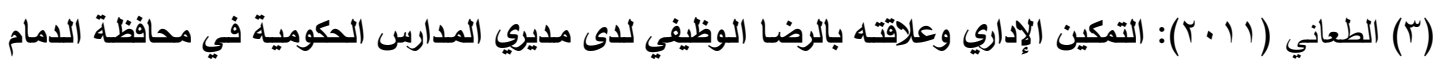

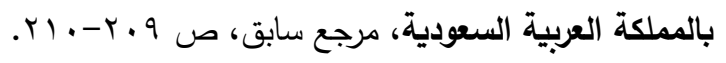




\section{العوامل المؤثرة على فعالية التمكين الإداري في المؤسسات التعليمية:}

تتمثل أهم العوامل (') المؤثرة على التمكين في المؤسسات التعليمية في: الهويـة، الهدف الذي يؤكد على استمرارية الحياة، التوجه، الهيكل، القيم الاساسية، نمط القيادة الملتزم بالمشورة والمشاركة في صنع القرار ، الثقة المتبادلة بأن الثخص المفوض سوف يقوم بالمهمة المطلوبـة بكفاءة وفعاليـة، الثفافية، التنسيق وروح الفريق، ودعم المهارات الإداريـة مـن خـلال التدربب والتحديث المستمر •

كما تتمثل(؟) أهم العوامل التي تساهم في التمكين وتؤثر عليه في المؤسسات التعليمية فيما يلي: الانشطة ذات المعنى خلال اليوم، عملية التعلم، توافر الضروريات الأساسية، الثقافة المواتية بالمنظمة، والتعاون بين العاملين.

\section{مراحل وخطوات تطبيق التمكين الإداري في المؤسسات التعليمية:} يمكن إيجاز عملية التمكين في أربعة مراحل رئيسية متتالية والتي تتمثل () في: مرحلـة التضـمين: وتعني الاشتمال على كل العاملين المهمشين والغير مشـاركين في عملية صنع القرار - ع مار مرحلـة المعلومـات: وتشير إلى الوصـول إلى المعلومـات من خـلال نشر الوعي بين العاملين وتبادل المعرفة.

مرحلة التأثير : وتعني تمكين الأفراد أو المجموعة من التأثير على العملية التعاونية. مرحلـة التكامل: والتي تعبر عن تكامل الأفراد مـع غيرهم من المشاركين في المواقف المشـابهة مـن خـلال المسـاعدة الذاتيـة ودعم التعليم ومجمعـة الفعل الاجتمـاعي وبنـاء شبكة الاتصال والتواصل.

(1) Villegas, Belinda Sanchez. "Factors influencing administrators' empowerment and financial management effectiveness." Procedia-Social and Behavioral Sciences 176 (2015). P 471-472.

(2) Ooms, I. A. Educational factors that contribute to empowering Zimbabwean refugee children's social and cognitive well-being. MS thesis. 2015. P 17-20.

(3) Vij, Nidhi. "Building capacities for empowerment: The missing link between social protection and social justice: Case of social audits in Mahatma Gandhi National Rural Employment Guarantee Act in India." International conference: Social protection for social justice. 2011. P 7-9. 


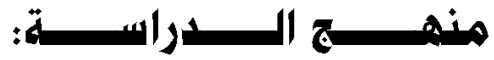

في سبيل اختبار فرضيات الدراسة وتحقيق أهدافها، اعتمدت الدراسة على المنهج الكمي (الوصفي التحليلي)، والذي يتم استخدامه لوصف ظاهرة أو مشكلة معينة، وتصويرها كميًا عن طريق جمـع البيانـات والمعلومـات الأولية عن تلك الظـاهرة، وتصنيفها، وتحليلها، وإخضـاعها

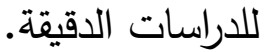

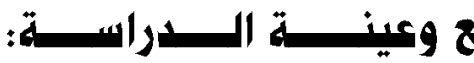

يتكون مجتمع الدراسة من المديرين ومساعديهم في مدارس التعليم الأساسي في محافظة ظفـار بسلطنة عمـان والبالغ عددها عـ ا مدرسـة. وذلك وفقـاً للإحصـائية الصـادرة عن وزارة

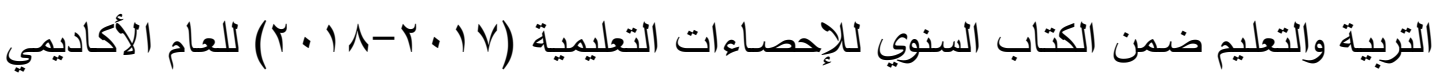
$\cdot r \cdot 1 \Lambda / r \cdot 1 V$

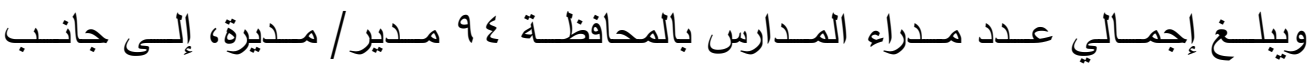

عـدد VIV مسـاعداً للمـدير ذكــوراً وإناثـاً. ويوضــح الجـدول (ع) حجــم المجتمـع الكلـي وعينة الدراسة ومعدل الإستجابة.

جلول (§) مجتمع وعينة الدراسة ومعدل الإستجابة

\begin{tabular}{|c|c|c|c|c|}
\hline نسبة & علد الإستمارات & علد الإستمارات & حجم المجتمع & 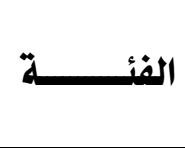 \\
\hline$\% 9,, 7$ & 71 & vo & $9 \xi$ & المدراء \\
\hline$\% r r$ & 70 & 9. & IIr & مساعدي المدراء \\
\hline$\% \wedge \cdot, 7$ & Irr & 170 & rII & الإجمالي \\
\hline
\end{tabular}

مـن خـلال الجـدول (ع) يتضــح أن مجتمـع الدراسـة يتكـون مـن عـدد الب مـديراً ومساعداً للمدير مبن

ويوضـح الجدول (0) توزيـع عينـة الدراسـة من المديرين/ المديرات ومسـاعديهم حسب مجموعة من المتغيرات الديموجرافية وهي:

$$
\begin{aligned}
& 1 \text { - الوظيفية. } \\
& \text { r- المؤهل العلمي. } \\
& \text { ب-سنوات الخبرة. }
\end{aligned}
$$




\section{جلول (0) توزيع عينة الدراسة من المدراء ومساعديهم حسب الوظيفية والمؤهل العلمي وسنوات الخبرة}

\begin{tabular}{|c|c|c|c|c|}
\hline النسبــــة المئـــــــــــة & التكـــــرار & الفئــــــــــة & المتفـــــير & مـ \\
\hline 01,1 & 71 & 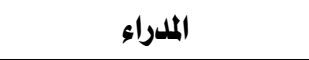 & \multirow{2}{*}{ الوظيفة } & \multirow{2}{*}{1} \\
\hline$\{\wedge, 9$ & 90 & مساعدي المدراء & & \\
\hline $1 .$. & irr & \multicolumn{3}{|c|}{ المجمـــــــــــع } \\
\hline ir,• & 19 & 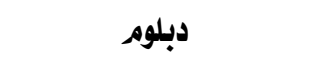 & \multirow{4}{*}{ المؤهل العلمي } & \multirow{4}{*}{ r } \\
\hline vr, & qr & بكالوريوس & & \\
\hline 10, & r. & ماجستير & & \\
\hline- & - & دكتوراه & & \\
\hline $1 .$. & Irr & \multicolumn{3}{|c|}{ المجمــــــــــع } \\
\hline 7,1 & 9 & أقل من ه سنوات & \multirow{4}{*}{ علد سنوات الخبرة } & \multirow{4}{*}{$r$} \\
\hline$r, 1$ & ru & ه سنوات لأقل من · سنوات & & \\
\hline M & r६ & •ا سنوات لأقل من 10 سنة & & \\
\hline $0 \leqslant, 1$ & vr & اسنة فأكثر & & \\
\hline $1 . \cdot$ & irr & \multicolumn{3}{|c|}{ المجمـــــــــــع } \\
\hline
\end{tabular}

أداة الــدراب

في هذه الدراسة، تم استخدام الاستبيان كأداة لجمع البيانات الأولية.

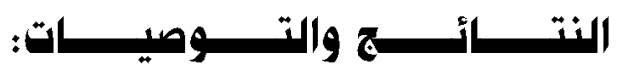

هدفت هذه الدراسـة إلى دراسـة تأثير تطبيق أبعاد التمكين الإداري في مدارس التعليم

الأساسي في سلطنة عمان، وفيما يلي أهم النتائج التي توصلت إليها الدراسة:

1- هنالك تفويض للسلطة لمديري مدارس التعليم الأساسي ومساعديهم بمحافظة ظفار من

جانب إدارة المديرية العامة للتربية والتعليم بالمحافظة.

ץ-تحقيق التمكين الإداري داخل مدارس التعليم الأساسي بمحافظة ظفار من خلال تشجيع

$$
\text { العمل الجماعي والتعاون بين جميع الأطراف داخل المدرسة. }
$$

ب- توفر المديريـة بـرامج تدريبيـة لكل مـن الإدارة المدرسية، والمدرسين، والهيئـة الإداريـة

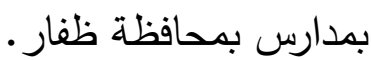


؟- وجود عملية إتصال فعال بين مديري مدارس التعليم الأساسي ومساعديهم من جهة، وجميع الفئات الأخرى داخل المدارس-وخاصة المعلمين-من جهة أخرى.

ه- بينت النتائج أن معظم المدراء ومساعديهم يقفون موقف الحياد تجاه أغلبية العناصر

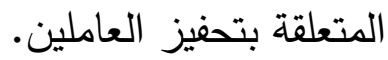
وبناء على النتائج السابقة، توصي الدراسة بالآتي: ا-مـنح إدارات المدارس المزيــ مـن الصـلاحيات في حل المشكلات المدرسية التي قد تواجهم بما يتناسب مع طبيعة المكان والزمان والأفراد. r- عمل ورش خاصة لتطبيق مبدأ العمل الجماعي في المدارس بشكل مستمر ، وتخصيص لجان مختصة تتابع بذلك باستمرار • r- ضرورة توفير الحوافز المادية والمعنوية لإدارات المدارس، لتعزيز شعورهم بأهمية العمل الإداري، والعمل على الإبداع والابتكار في العمل الددرسي.

\section{الدراسات المستقبلية المقترحة}

في ضوء في ضوء ما أسفرت عنه نتائج هذه الدراسة، فإن الباحثة تقترح إجراء دراسات مماثلة للدراسة الحالية لمعرفة درجة التمكين الإداري بمحافظات أخرى بالسلطنة. 


\section{المســـــــ}

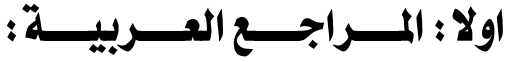

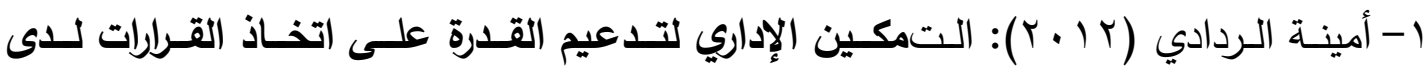
المشرفين التربويين بمدينة مكة المكرمة، جامعة أم القرى ، المملكة العربية السعودية.

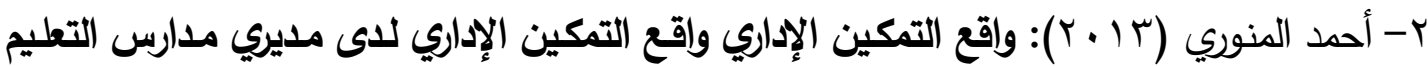
ما بعد الأساسي في محافظة الباطنة شمال بسلطنة عمان، جامعة نزوى، سلطنة عمان.

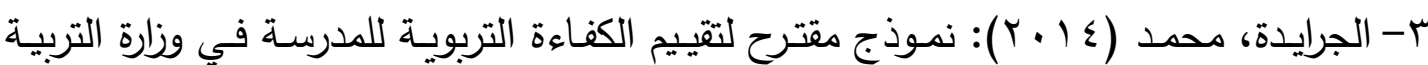
والتعليم بسلطنة عمان. مجلة المنارة، الأردن، م(· (Y)، ع (Y)، ص99 V.

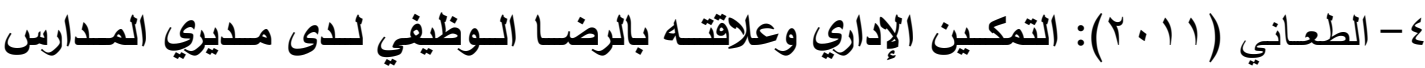
الحكومية في محافظة الامام بالمملكة العربية السعودية، مرجع سابق، ص 9 ـ ب- • آ. ه- تقرير مؤشر دافوس لجودة التعليم ( 1 ( ب). مؤشر دافوس لجودة التعليم في • ؛ ا من

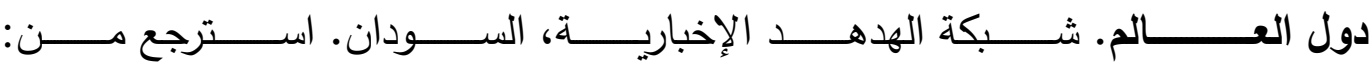
WWwW.facebook.com/alhodhodekhbarya צ- جمـال الدين وآخرون (10 • ب): التمكين الإداري "المفهـوم والأبعـاد"، مرجع سـابق، ص $. \leqslant V \cdot-\varepsilon \leqslant 1$

V- خالد الشعبان (^ • . ץ): الجودة الشـاملة مدخل لتطوير الإدارة المدرسية بمدارس الدمج الحكوميـة بمراحلهـا الـثلاث بمحافظـة جـدة. رسـالة ماجستير ، جامعـة أم القرى، المملكـة

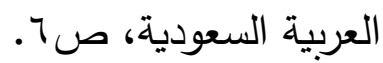
^-زليخا المنوري، (0 1 ب): تطوير إدارة الجودة في مدارس التعليم الأساسي بسلطنة عمان في الضـوء الفكر التربـوي المعاصـر (تصـور مقتـرح)، رسـالة دكتوراة، جامعـة القـاهرة،

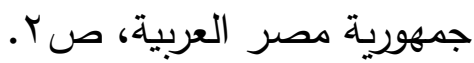
9- سلامة عبد العظيم حسين (^ . . ץ): الجودة والاعتمـاد التربوي. الإسكندرية: دار الجامعة الجديدة، ص90 19. 


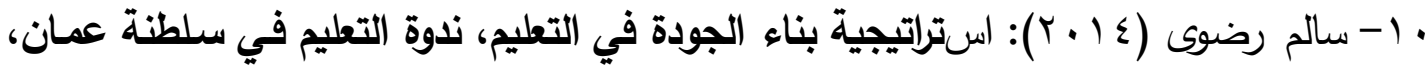

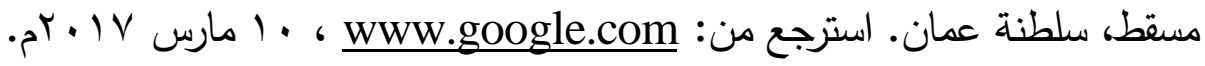

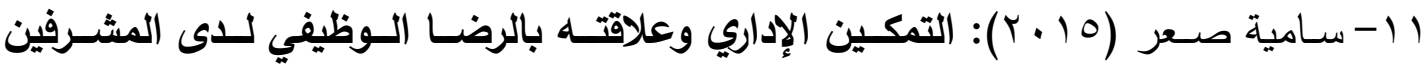
التربويين بمحافظة ظفار ، رسالة ماجستير ، جامعة ظفار، سلطنة عمان.

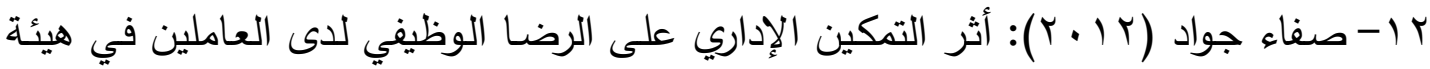

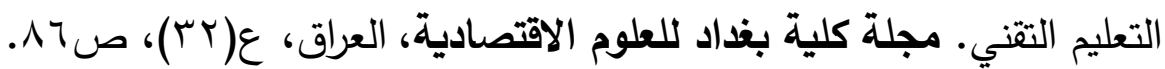

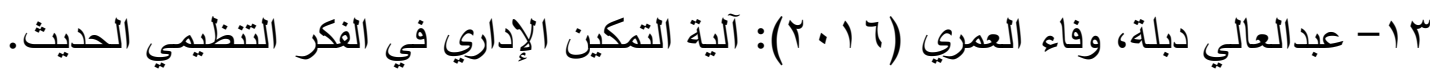

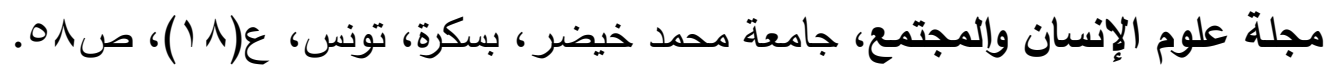

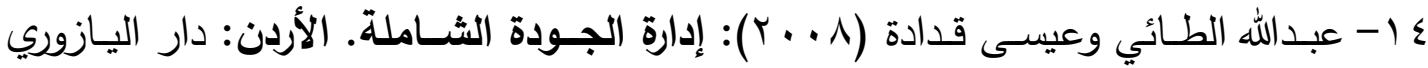

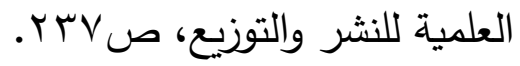

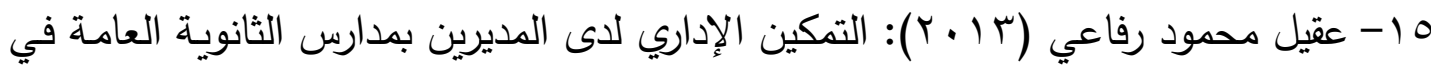

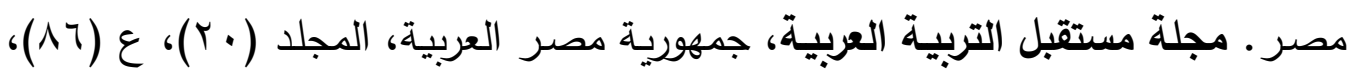

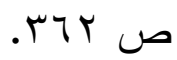
1 ا - منظمة الاقتصاد والتعاون الدولية(10 • ب): أفضل تسع دول عربية في مستوى التحصيل

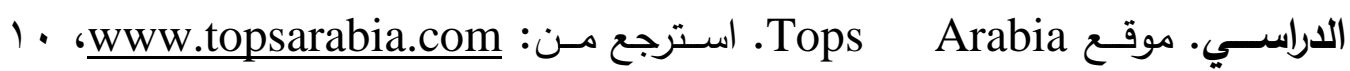

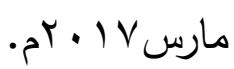

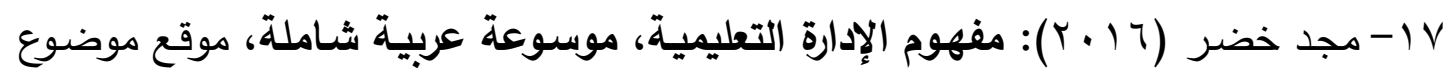
دوت كوم، الأردن. استرجع من:

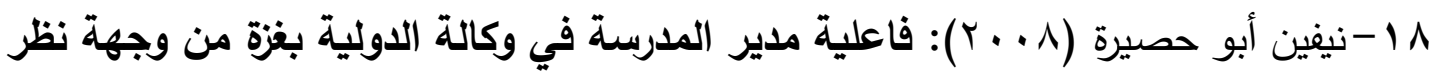

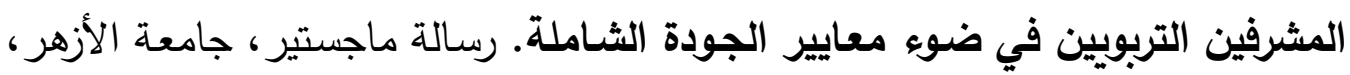

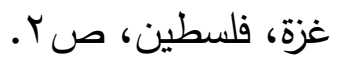

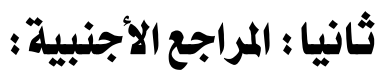

1- Alshbiel, Seif Obeid. "The Impact of the Managerial Empowerment in the Performance of Investment Funds in the Jordanian Public Universities." Global Journal of Management And Business Research, Volume 14 Issue 5 Version 1.0 Year 2014 , (2015). P4. 
2- Fandiño, Yamith J. "Research as a means of empowering teachers in the 21st century." Educación y educadores 13.1 (2010). P112.

3- Hamzeh Al haar. The Impact of Administrative Empowerment on the Organization Performance at Jordanian Industrial Companies. Canadian Social Science, (2016). Vol(12), No(1).

4- Ooms, I. A. Educational factors that contribute to empowering Zimbabwean refugee children's social and cognitive well-being. MS thesis. 2015. P 17-20.

5- Vij, Nidhi. "Building capacities for empowerment: The missing link between social protection and social justice: Case of social audits in Mahatma Gandhi National Rural Employment Guarantee Act in India." International conference: Social protection for social justice. 2011. P 7-9.

6- Villegas, Belinda Sanchez. "Factors influencing administrators' empowerment and financial management effectiveness." ProcediaSocial and Behavioral Sciences 176 (2015). P 471-472.

7- Weaam Khalayleh, Raed Masadeh, Musa Al lozi The Role of Administrative Empowerment on the Work teams Performance: A Literature Review. Centre of Excellence for Scientific \& Research Journalism, (2018). Vol(4), No(3). 